\title{
Fluorescence in situ hybridization is superior for monitoring Epstein Barr viral load in infectious mononucleosis patients
}

Pengfei Cao 1,2,3, Meili Zhang 1,2,5, Wei Wang ${ }^{1,2,4}$, Yafei Dai ${ }^{1,2,4}$, Buqing Sai ${ }^{1,2,4}$, Jun Sun ${ }^{1,2,4}$, Lujuan Wang ${ }^{1,2,4}$, Fan Wang ${ }^{1,2,4}$, Guiyuan Li $\mathrm{L}^{1,2,4^{*}}$ and Juanjuan Xiang ${ }^{1,2,4^{*}}$

\begin{abstract}
Background: Epstein Barr virus (EBV) plays a causal role in some diseases, including infectious mononucleosis, lymphoproliferative diseases and nasopharyngeal carcinoma. Detection of EBV infection has been shown to be a useful tool for diagnosing EBV-related diseases. In the present study, we compared the performance of molecular tests, including fluorescence in situ hybridization (FISH) and EBV real-time PCR, to those of serological assays for the detection of EBV infection.

Methods: Thirty-eight patients with infectious mononucleosis (IM) were enrolled, of whom 31 were diagnosed with a mild type, and seven were diagnosed with IM with haemophagocytic lymphohistiocytosis and chronic active EBV infection. Twenty healthy controls were involved in the study. The atypical lymphocytes in peripheral blood were detected under a microscope and the percentage of positive cells was calculated. EBV DNA load in peripheral blood was detected using real-time PCR. The FISH assay was developed to detect the EBV genome from peripheral blood mononuclear cells (PBMC). Other diagnosis methods including the heterophil agglutination (HA) test and EBV-VCA-IgM test, to detect EBV were also compared. SPSS17.0 was used for statistical analysis.

Results: In all, 5-41\% atypical lymphocytes were found among the PBMC in mild IM patients, whereas 8-51\% atypical lymphocytes were found in IM patients with haemophagocytic lymphohistiocytosis and chronic active EBV infection patients. There was no significant difference in the ratios of atypical lymphoma between patients of the different types. We observed that $71.2 \%$ of mild IM patients and $85.7 \%$ of IM patients with haemophagocytic lymphohistiocytosis and chronic active EBV infection patients were positive for EBV-VCA-IgM. EBV-VCA-IgM was negative in all healthy control subjects. In addition, $67.1 \%$ of mild IM patients tested heterophile antibody positive, whereas $71.4 \%$ of IM patients with haemophagocytic lymphohistiocytosis and chronic active EBV infection tested positive. EBV DNA detected using real-time PCR was observed in $89.5 \%$ of these IM patients. The EBV genome was detected by the FISH assay in $97.4 \%$ of the IM patients. The EB viral loads detected by FISH and real-time PCR increased with the severity of IM. The EBV genome was detected in almost all the PBMC of IM with haemophagocytic lymphohistiocytosis and chronic active EBV infection patients.
\end{abstract}

Conclusion: Molecular tests, including FISH and EBV real-time PCR, are more sensitive than serological assays for the detection of EBV infection. The FISH assay detecting EBV copies in unfractionated whole blood is preferable and superior to plasma real-time PCR in its reflection of the absolute viral burden circulating in the patients.

Keywords: EB viral load, Infectious mononucleosis, Real-time PCR, FISH

\footnotetext{
*Correspondence: ligy@csu.edu.cn; lgy@csu.edu.cn; xiangjj@csu.edu.cn

'The Key Laboratory of Carcinogenesis of the Chinese Ministry of Health,

Xiangya Hospital, Central South University, Changsha, Hunan, China

Full list of author information is available at the end of the article
} 


\section{Background}

Epstein Barr virus (EBV) is a $\gamma$-herpesvirus that infects at least $90 \%$ of the population worldwide [1]. In a majority of individuals, EBV infection is asymptomatic. EBV infection in adolescents and young adults frequently results in infectious mononucleosis (IM). IM presents as a mild EBV infectious illness and is self-limiting. However, EBV infection can also cause IM with haemophagocytic lymphohistiocytosis (HLH) or chronic active EBV infection (CAEBV). Both EBV-HLH and CAEBV are life-threatening complications [2]. Factors involved in the occurrence of IM with severe complications include immune status and polymorphisms in HLA-A01 or interleukin 10 [3, 4].

The clinical presentations, presence of atypical lymphocytes in peripheral blood, and positive heterophile antibody test are used for the diagnosis of IM. IM is not always considered early on; in particular, when there is a high level of viral upper-respiratory infections, diagnosis of mild EBV infection is difficult, if not impossible [5]. In patients with prolonged or vague symptoms, the diagnosis of acute IM can be easily missed. Rapid diagnosis can help the clinician become proficient with treatment. Serology tests are the main diagnostic strategy for the detection of EBV. Viral capsid antigens (VCAs), early antigens (EAs), and EBNAs encoded by the EBV genome are mostly used for serodiagnosis [6]. Serological tests for measuring antibodies to EBV are not usually positive until symptoms have been present for one week or more. False positive and false negative results are frequently observed [7]. High antibody titers against EBV-related proteins are not necessary for diagnosis because there can be a lack of serologic response in patients with a CAEBV infection [8]. Heterophile antibodies are not specific and do not develop in some patients. Only 59-81\% of IM patients over age 13 were positive for the heterophile antibody, and levels were even lower in children under age 13, especially early in the course of the illness [9]. Other EBV-related illnesses can also occur, including cancers such as Burkitt's lymphoma and autoimmune diseases. Severe and lasting disease can develop in the form of CAEBV or HLH in EBV-related malignancy, which shows markedly elevated levels of EBV DNA in the peripheral blood. However, the plasma levels of EBV DNA cannot simply be linked to the severity or spread of infection, because high levels of EBV DNA were found in the blood of both asymptomatic and exacerbated IM [10]. The link between the EB viral load and severity of symptoms has not yet been determined.

The measurement of EBV DNA in peripheral blood has been shown to be a useful tool for the diagnosis of EBV-related diseases. It has been suggested that quantitative viral load assessment is superior to qualitative detection [11]. Quantitative real-time EBV PCR performed using the plasma of patients resulted in an increase in the definitive diagnosis of primary EBV infection [12]. In situ hybridization detects EBV-encoded RNAs (EBERs) and is considered a good test for localizing latent EBV in tissue samples [7]. Here, we develop a new fluorescence in situ hybridization (FISH) probe with more than $3000 \mathrm{bp}$ to detect cellular EBV DNA. This technique allows for the quantitative analysis of EBV copy numbers in infected cells. This method can evaluate the severity of EBV infection and may be used as a marker for treatment.

\section{Patients, materials and methods}

\section{Patients}

Patients newly diagnosed with IM $(n=38)$ were included in this study. Twenty healthy people were enrolled as a control group. All cases enrolled in this study were identified between January 2013 and December 2015 at Xiangya Hospital, Central South University, China. The diagnosis of IM was made by clinical presentation, heterophile antibody test, EBV serological determinations and serum EBV-DNA detected by real time-PCR. Patients diagnosed with HLH or CAEBV were identified by persistent infectious mononucleosis-like symptoms. Thirty-one patients with mild IM suffered from fever, hepatosplenomegaly, lymphoadenopathy and elevated transaminase levels. In addition to the common symptoms, jaundice, hepatic dysfunction, and severe cytopenia could be seen in the seven patients with HLH or CAEBV. The clinical characteristics of the 38 patients are listed in Table 1 . The patients were informed about the sample collection and signed informed consent forms. Collection and use of samples were approved by the ethical review committees of Xiangya Hospital, Central South University. Table 1 the characteristics of IM patients

2. Atypical Lymphocytes Human peripheral blood mononuclear cells (PBMCs) were isolated from healthy donors and infectious mononucleosis patients using density gradient centrifugation. The atypical lymphocytes were detected using Wright staining (Baso Company, China). The atypical lymphocytes in the peripheral blood were detected under microscope, and the percentage of positive-stained cells was calculated.

3. Heterophil Agglutination test

Sera from patients and healthy control were tested for heterophil antibodies using sheep erythrocyte agglutination. All sera were inactivated. The serum of each patient was absorbed with an equal volume of washed sheep erythrocytes. Any agglutination was considered to be due to IM heterophile antibodies.

4. Detection of peripheral blood EBV - VCA - IgM 
Table 1 The characteristics of IM patients

\begin{tabular}{|c|c|c|c|}
\hline & $\begin{array}{l}\text { MILD } \\
(n=31)\end{array}$ & $\begin{array}{l}\text { IM-HLH or IM-CAEBV } \\
(n=7)\end{array}$ & $P$-value \\
\hline \multicolumn{3}{|l|}{ Gender } & $>0.05$ \\
\hline male & $18(58.1 \%)$ & $3(42.9 \%)$ & \\
\hline female & 13(41.9\%) & $4(57.1 \%)$ & \\
\hline \multicolumn{3}{|l|}{ Age } & $>0.05$ \\
\hline 0-14 & $24(77.4 \%)$ & $5(71.4 \%)$ & \\
\hline$>14$ & $7(22.6 \%)$ & $2(28.6 \%)$ & \\
\hline \multicolumn{3}{|l|}{ Leukocyte count } & $>0.05$ \\
\hline $4 \times 10^{9} / \mathrm{L}$ & $7(22.6 \%)$ & $2(28.6 \%)$ & \\
\hline $4-10 \times 10^{9} / \mathrm{L}$ & $8(25.8 \%)$ & $1(14.3 \%)$ & \\
\hline$\geq 10 \times 10^{9} / \mathrm{L}$ & $16(51.6 \%)$ & $4(57.1 \%)$ & \\
\hline Median(range) & $10.85(1.2-43.0)$ & $14.9(1.5-61.0)$ & \\
\hline \multicolumn{3}{|l|}{ ALT or AST } & $>0.05$ \\
\hline high & $27(87.1 \%)$ & $7(100 \%)$ & \\
\hline normal/low & $4(12.9 \%)$ & $0(0 \%)$ & \\
\hline \multicolumn{3}{|l|}{ coagulopathy } & $>0.05$ \\
\hline positive & $22(74.2 \%)$ & $6(85.7 \%)$ & \\
\hline negative & $9(25.8 \%)$ & $1(14.3 \%)$ & \\
\hline \multicolumn{3}{|l|}{ ferritin high } & $>0.05$ \\
\hline high & $24(77.4 \%)$ & $6(85.7 \%)$ & \\
\hline normal/low & $7(22.6 \%)$ & $1(14.3 \%)$ & \\
\hline \multicolumn{3}{|l|}{ Triglyceride } & $>0.05$ \\
\hline high & $24(77.4 \%)$ & $6(85.7 \%)$ & \\
\hline normal/low & $7(22.6 \%)$ & $1(14.3 \%)$ & \\
\hline \multicolumn{3}{|l|}{ hepatosplenomegaly } & $>0.05$ \\
\hline yes & $22(71.0 \%)$ & $6(85.7 \%)$ & \\
\hline no & $9(29.0 \%)$ & $1(14.3 \%)$ & \\
\hline \multicolumn{3}{|l|}{ lymphoadenopathy } & $>0.05$ \\
\hline yes & $24(77.4 \%)$ & $5(71.4 \%)$ & \\
\hline no & $7(22.6 \%)$ & $2(28.6 \%)$ & \\
\hline \multicolumn{3}{|c|}{ Days after onset of disease } & $<0.05$ \\
\hline average time & $34.8 d$ & $119.7 d(4 / 7,3$ decreased $)$ & \\
\hline
\end{tabular}

A recombinant immunofluorescent antibody (RIFA) test was performed to quantitatively detect human serum IgM antibodies to EBV-VCA (Focus Diagnostics, USA). The experiments were conducted in accordance with the manufacturer's instructions. In brief, after incubation with appropriately diluted serum, the slides prepared with recombinant EBV VCA antigen were washed with phosphate buffered saline, and fluorescence in isothiocyanate-conjugated anti-human IgM was applied to each well at the appropriate concentrations. The slides were mounted with buffered glycerol and observed under a fluorescence microscope.
5. Real-time PCR for EBV

Quantitative real-time EBV PCR was performed in plasma samples collected from IM patients and healthy controls using an Epstein-Barr virus DNA Quantitative Fluorescence Diagnostic Kit (Sansure Biotech, Hunan, China). Peripheral blood was obtained from patients when they presented at the hospital. Viral DNA was extracted, and the PCR reaction was performed according to the instructions. The qPCR protocol was $94{ }^{\circ} \mathrm{C}$ for $5 \mathrm{~min}$, followed by 45 cycles of $94{ }^{\circ} \mathrm{C}$ for $15 \mathrm{~s}$ and $57^{\circ} \mathrm{C}$ for $30 \mathrm{~s}$. The EBV copy number was calculated according to the standard curve.

6. Cell Culture

The human Burkitt lymphoma cell lines P3HR-1, RAJI and BJAB were cultured in RPMI-1640 (HyClone, Life Sciences, USA) supplemented with penicillin $\mathrm{G}(100 \mathrm{U} / \mathrm{mL})$, streptomycin $(100 \mathrm{mg} / \mathrm{mL})$ and $10 \%$ foetal calf serum. Cells were grown at $37^{\circ} \mathrm{C}$ in a humidified atmosphere of $5 \% \mathrm{CO}_{2}$ and routinely subcultured using a $0.25 \%(w / v)$ trypsin-EDTA solution.

7. Fluorescence in situ hybridization An EBV-specific probe was prepared from EBV, which was obtained from the productive EBV B-cell lineage p3HR-1. The culture media were collected from P3HR-1. After repeated freezing and thawing, the collected media were centrifuged for 20 mins at 3000 RPM. The supernatant was collected and filtered with a $0.45-\mu \mathrm{m}$ membrane filter. EB viral DNA was extracted from a sample aliquot of $250 \mu \mathrm{L}$ using the Qiagen QIAamp Virus MinElute Spin Kit (Qiagen, Valencia, CA, USA) and then immediately frozen until use. DNA probes of 3267 bp long were generated via PCR.

Forward primer: $5^{\prime}$-TTCGTCTTGCTCTATTCAC CCTTAC-3' (EBV genome $5 \sim 28$ );

Reverse primer: $5^{\prime}$-CACTGTAATGAAGACGTT GGAACAG-3' (EBV genome of $3271 \sim 3247$ ).

The PCR reaction was as follows: $94{ }^{\circ} \mathrm{C}$ for $1 \mathrm{~min}$ and 30 cycles of $94{ }^{\circ} \mathrm{C}$ for $30 \mathrm{~s}, 1 \mathrm{~min} 55^{\circ} \mathrm{C}, 72{ }^{\circ} \mathrm{C}$ for $5 \mathrm{~min}$, and $72^{\circ} \mathrm{C}$ for $10 \mathrm{~min}$. The 3267-bp PCR product was collected using a QIAquick PCR Purification Kit (Qiagen, Valencia, CA, USA) and labelled with biotin-dUTP using a randomly-primed labelling method (Roche, Mannheim, Germany). The reaction was terminated by heating at $65^{\circ} \mathrm{C}$ for $10 \mathrm{~min}$. PBMCs from patients were prepared and smeared on the slides. The slides were directly immersed in water $\left(80^{\circ} \mathrm{C}\right)$ for $5 \mathrm{~min}$, denatured in $70 \%$ fomamide-2XSSC at $70{ }^{\circ} \mathrm{C}$ for $2 \mathrm{~min}$ and dehydrated in a series of ethanol concentrations, followed by air drying. The hybridizaiton mixture containing $50 \mathrm{ng}$ of probe and $5 \mu \mathrm{g}$ of salmon sperm DNA was heated at $78{ }^{\circ} \mathrm{C}$ for $5 \mathrm{~min}$ to denature the 
probe, followed by preannealing at $37^{\circ} \mathrm{C}$ for $1 \mathrm{~h}$. The slides were incubated with the hybridization mixture overnight at $37^{\circ} \mathrm{C}$ for $14 \mathrm{~h}$. Following hybridization, the slides were washed in 50\% formamide/2XSSC and then $0.1 \mathrm{XSSC}$, followed by washing with $0.05 \%$ Triton $\mathrm{X}-100 / 2 \times \mathrm{SSC}$ at $42{ }^{\circ} \mathrm{C}$. The blocked slides were incubated with avidin-FITC for $30 \mathrm{~min}$ at room temperature, followed by incubation with anti-FITC. After washing, drying and mounting, the slides were examined under fluorescence microscopy. The cut-off value was based on the results of twenty healthy people in the control group. Two hundred cells in every control member and every patient were observed to calculate the average number of fluorescent particles in each cell. A fluorescent particle number less than the cut-off value (4-5 particles/cell) was considered negative.

8. Statistical analysis

Statistical analyses were performed using SPSS 17.0. A $p$ value of less than 0.05 was considered significant.

\section{Results}

\section{Specificity and sensitivity of FISH probe for EBV} infection

The specificity and sensitivity of the FISH probe for EBV were determined in the EBV-negative cell line BJAB and EBV-positive cell lines P3HR-1, RAJI and EBV-infected BJAB. As shown in Fig. 1, in situ hybridization generated fluorescent spots in P3HR-1, RAJI and EBV-infected BJAB cells. However, in the EBV-negative BJAB cell line, no fluorescent particles were detected by FISH (Fig. 1). This suggests that hybridization with the 3267-bp EBV sequence probe was specific and sensitive for viral DNA.

2. Molecular tests are superior to serological tests for monitoring EBV infection in IM

Atypical lymphocytes were found in 5-41\% (median positivity rate of $17.8 \%$ ) of PBMCs from mild IM patients, whereas $8-51 \%$ (median positivity rate of 21.6\%) of PBMCs from IM-HLH and IM-CAEBV patients harbouredatypical lymphocytes (Fig. 2). There was no significant difference in the percentage of patients with more than $10 \%$ atypical lymphocytes between in the mild IM patients and the IM-HLH and IM-CAEBV patients (83.9\% vs $85.7 \%, p>0.05$ ) (Table 2).

Detection of IgM against VCA was performed with a semi-quantitative recombinant immunofluorescent antibody (RIFA) test on IM patients; $71.2 \%$ of mild IM patients and $85.7 \%$ of IM-HLH and IM-CAEBV patients were positive for EBV-VCA-IgM. EBV-VCAIgM was negative in all healthy control patients. However, neither IM-HLH nor IM-CAEBV patients $\mathrm{d}$

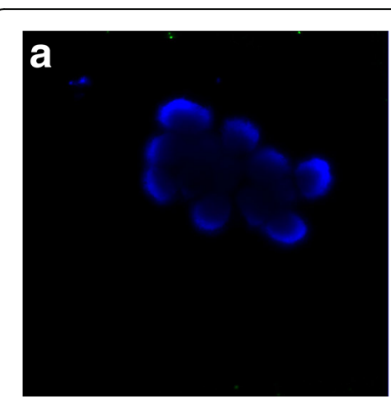

BJAB

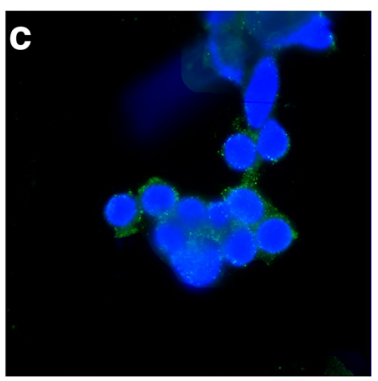

P3HR-1

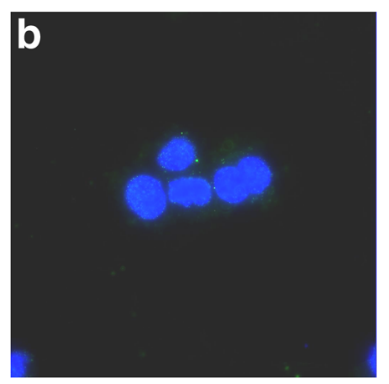

$\mathrm{BJAB}+\mathrm{EBV}$

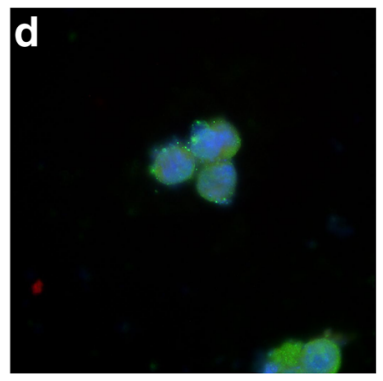

RAJI
Fig. 1 FISH assay for EBV in EBV positive and negative cell lines. Fluorescence in situ hybridization for detection of the EBV genome was performed in EBV-negative cell line BJAB (a), EBV-infected BJAB (b), and EBV positive cell lines P3HR-1 (c) and RAJI (d)

had higher antibody titers against EBV-VCA than mild IM patients. In all, $67.1 \%$ of mild IM patients were heterophile antibody-positive, whereas $71.4 \%$ of IM-HLH and IM-CAEBV patients tested positive. Serum EBV DNA was defined using real-time PCR. EBV DNA was detected in 34 of 38 enrolled patients (89.5\%), ranging from $<500$ to $8.26 \times 10^{7} \mathrm{copies} / \mathrm{ml}$. Four of the 38 clinically diagnosed IM patients were EBV DNA-negative according to plasma real-time PCR. Plasma samples obtained from the 20 control individuals were all EBV DNA negative. In situ hybridization for EBV DNA showed fluorescent spots in PBMCs obtained from 37 of 38 IM patients (positivity rate of 97.4\%). According to the clinical diagnosis, the sensitivity values for atypical lymphocytes, the HA test, EBV-VCA-IgM, EBV DNA PCR and FISH were 84.2\%, 68.4\%, 76.3\%, 89.5\% and $97.4 \%$, respectively. The sensitivity of the FISH test was significantly higher than that of atypical lymphocytes, the heterophile antibody test or EBV VCA-IgM (Table 2).

\section{FISH is superior to plasma EBV-DNA real-time} PCR

The real-time PCR assay on the plasma of IM patients revealed that mild IM patients have fewer EBV genome copies than IM-HLH and IM-CAEBV patients (Table 3 ). Thirty-one of mild IM patients showed viral loads ranging from $<500-9.37 \times 10^{5}$ 

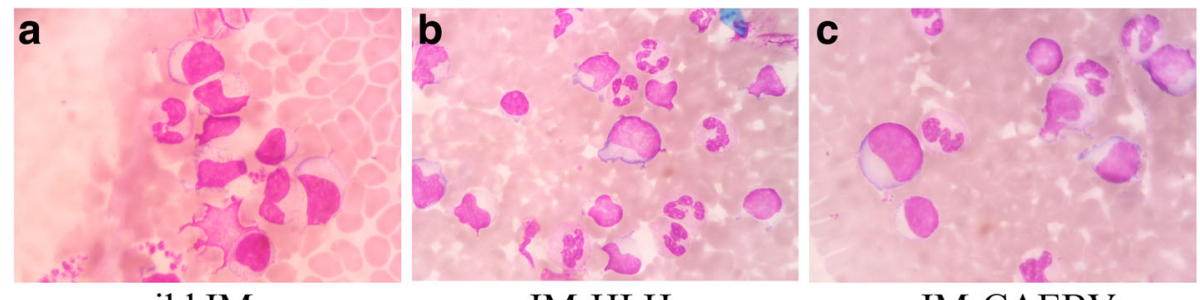

mild IM

IM-HLH

IM-CAEBV

Fig. 2 Atypical Lymphocytes in PBMCS of IM patients. a: Atypical lymphocyte in PBMC of mild IM patients; b: Atypical Lymphocyte in PBMC of IM-HLH; c: Atypical Lymphocyte in PBMC of IM-CAEBV ( $\times 1000$, Wright-Giemsa)

copies/ml, while 7 of IM-HLH and IM-CAEBV patients demonstrated viral loads ranging from $3.75 \times 10^{3}-8.26 \times 10^{7}$ copies $/ \mathrm{ml}$. There was a significant difference between the mild IM patients and the IM-HLH and IM-CAEBV patients.

However, plasma levels of EBV DNA cannot be directly linked to the severity of IM.

The FISH assay was performed with PBMCs from IM patients. The genome copy number was much lower in the PBMCs from mild IM patients than the IM-HLH and IM-CAEBV patients. Compared to the cells in mild IM patients with 10 to $20 \mathrm{EBV}$ genomes per cell (average fluorescent particles $=11.32$ ), cells from IM-HLH and IM-CAEBV patients revealed 35 to $50 \mathrm{EBV}$ genomes per cell (average fluorescent particles $=45.24$ ), suggesting that the viral load increased with IM severity (Table 3 and Fig. 3, $P<0.05$ ). The cut-off value of our EBV FISH was 4.02. EBV fluorescent particles were detected by FISH in 37 out of 38 IM patients. More than 90\% (ranging from $83.5 \%$ to $100 \%$ ) of PBMCs which may include T cells, B cells or NK cells, in IM-HLH and IMCAEBV patients, were EBV viral DNA-positive according to the FISH test, whereas many fewer PBMCs were EBV viral DNA-positive in mild IM patients (3\%-72.5\%). This indicates that the method is good for the identification of IM with severe complications.

\section{Discussion}

Some lymphoproliferative diseases (PTLD) are closely linked to EBV infection. However, infection of EBV is never associated with any symptoms in the majority of individuals. The association between the EBV infection status and lymphoproliferative disorders remains unknown.
Stochastic loss of viral nucleic acids can be observed in EBV-related disease, suggesting the hit-and-run effects of EBV. EBV-driven malignant disease is closely linked to the viral latent state. IM is a mild lymphoproliferative disorder that is in most cases caused by EBV. Every organ can be involved in IM, andlife-threatening complications can occur. Diagnosis of IM is based on clinical, haematological findings and confirmed with a positive test for heterophile antibodies [13]. Serological tests are always used to analyze EBV-related antibodies. However, there was a greater variation in sensitivity and specificity. The seronegative window period varies among patients. The positivities obtained by the EBV-VCA-IgM and HA tests in this study are $76.3 \%$ and $68.4 \%$ for IM patients. Although some commercial serological tests for detection of EBV infection resulted in improvement in sensitivity and specificity, the titer against EBV-related antigens cannot be directly linked to the severity of IM and cannot differentiate between primary infection and reactivation [13]. Real-time PCR can provide a useful tool for the early diagnosis of IM in cases of inconclusive serological results [14]. At present, the best test for diagnosing and monitoring EBV infections is the blood viral load test, which is usually performed using a PCR platform [15]. The DNA of the virus detected by real-time PCR was detected in $89.5 \%$ of IM patients; 27 of 31 samples in the mild IM group and all samples in IM-HLH and IM-CAEBV group showed EBV DNA positivity by PCR. Detection of EBV by the FISH assay acquired $97.4 \%$ positivity, indicating that the molecular test more sensitively detects EBV infection, consistent with the conclusions of Horwitz [13] and Balfour HH's [14]. In the present study, we found high numbers of genome copies detected by direct visualization of EBV genomes using in situ hybridization. In situ hybridization of

Table $\mathbf{2}$ The comparison of the sensitivity of serology tests and molecular tests

\begin{tabular}{llllll}
\hline & $\begin{array}{l}\text { Atypical Lymphocytes } \\
(>10 \%)\end{array}$ & HA test & EBV-lgM & EBV PCR & FISH \\
\hline mild IM $(n=31)$ & $26 / 31(83.9 \%)$ & $21 / 31(67.7 \%)$ & $23 / 31(71.2 \%)$ & $27 / 31(87.1 \%)$ & $30 / 31(96.8 \%)$ \\
IM-HLH or IM-CAEBV $(n=7)$ & $6 / 7(85.7 \%)$ & $5 / 7(71.4 \%)$ & $6 / 7(85.7 \%)$ & $7 / 7(100 \%)$ & $7 / 7(100 \%)$ \\
Total(\%) & $32 / 38(84.2 \%)^{*}$ & $26 / 38(68.4 \%)^{* *}$ & $29 / 38(76.3 \%)^{*}$ & $34 / 38(89.5 \%)$ & $37 / 38(97.4 \%)$ \\
\hline
\end{tabular}

*Compare to FISH, $P<0.05 ;{ }^{*}$ Compare to $\mathrm{FISH}, P<0.01$ 
Table 3 Clinical features and laboratory results of the 38 IM patients

\begin{tabular}{|c|c|c|c|c|c|c|c|}
\hline \multirow[t]{2}{*}{ Num } & \multirow[t]{2}{*}{ Clinical type } & \multirow{2}{*}{$\begin{array}{l}\text { HA } \\
\text { test }\end{array}$} & \multirow{2}{*}{$\begin{array}{l}\text { EBV-VCA } \\
\lg M\end{array}$} & \multirow{2}{*}{$\begin{array}{l}\text { RT-PCR } \\
\text { (copies/ml) }\end{array}$} & \multirow{2}{*}{$\begin{array}{l}\text { FISH positivity } \\
\text { (per } 100 \text { cells) }\end{array}$} & \multicolumn{2}{|c|}{ FISH fluorescent } \\
\hline & & & & & & particles & outcome \\
\hline 1 & mild & - & $1: 10$ & $3.65 \times 10^{3}$ & $61.5 \%$ & $8.52 /+$ & alive \\
\hline 2 & mild & + & - & $7.05 \times 10^{3}$ & $3.0 \%$ & $0.62 /-$ & alive \\
\hline 3 & mild & + & $1: 20$ & $6.26 \times 10^{5}$ & $66.0 \%$ & $11.42 /+$ & alive \\
\hline 4 & mild & - & $1: 160$ & $6.21 \times 10^{3}$ & $54.5 \%$ & $13.06 /+$ & alive \\
\hline 5 & mild & + & $1: 320$ & $4.75 \times 10^{5}$ & $56.5 \%$ & $13.78 /+$ & alive \\
\hline 6 & mild & - & - & $2.02 \times 10^{4}$ & $62.0 \%$ & $29.91 /+$ & alive \\
\hline 7 & mild & + & - & $4.35 \times 10^{4}$ & $42.5 \%$ & 7.78/+ & alive \\
\hline 8 & mild & + & $1: 640$ & $9.05 \times 10^{4}$ & $65.0 \%$ & $10.75 /+$ & alive \\
\hline 9 & mild & - & $1: 160$ & $7.32 \times 10^{5}$ & $57.5 \%$ & $11.35 /+$ & alive \\
\hline 10 & mild & + & $1: 160$ & $3.45 \times 10^{3}$ & $72.5 \%$ & $14.52 /+$ & alive \\
\hline 11 & mild & + & $1: 80$ & $5.09 \times 10^{5}$ & $63.0 \%$ & $7.89 /+$ & alive \\
\hline 12 & mild & - & 1:160 & $7.32 \times 10^{3}$ & $56.5 \%$ & $9.24 /+$ & alive \\
\hline 13 & mild & + & - & $3.26 \times 10^{3}$ & $70.5 \%$ & $6.28 /+$ & alive \\
\hline 14 & mild & - & $1: 80$ & $8.25 \times 10^{5}$ & $50.5 \%$ & $10.79 /+$ & alive \\
\hline 15 & mild & + & - & $6.32 \times 10^{3}$ & $63.0 \%$ & $11.24 /+$ & alive \\
\hline 16 & mild & - & - & $9.37 \times 10^{5}$ & $41.5 \%$ & $13.52 /+$ & alive \\
\hline 17 & mild & + & $1: 160$ & $8.02 \times 10^{5}$ & $67.5 \%$ & $14.36 /+$ & alive \\
\hline 18 & mild & + & $1: 80$ & $7.22 \times 10^{3}$ & $70.5 \%$ & $9.01 /+$ & alive \\
\hline 19 & mild & + & - & $6.91 \times 10^{4}$ & $52.0 \%$ & $19.43 /+$ & alive \\
\hline 20 & mild & - & $1: 20$ & $6.44 \times 10^{3}$ & $45.5 \%$ & $11.21 /+$ & alive \\
\hline 21 & mild & + & $1: 80$ & $4.28 \times 10^{5}$ & $35.5 \%$ & $12.36 /+$ & alive \\
\hline 22 & mild & + & $1: 20$ & $1.75 \times 10^{4}$ & $45.5 \%$ & $13.42 /+$ & alive \\
\hline 23 & mild & - & - & $3.92 \times 10^{5}$ & $72.5 \%$ & $14.53 /+$ & alive \\
\hline 24 & mild & + & $1: 320$ & $1.07 \times 10^{4}$ & $65.5 \%$ & $14.76 /+$ & alive \\
\hline 25 & mild & - & $1: 20$ & $<500$ & $42.0 \%$ & $13.23 /+$ & alive \\
\hline 26 & mild & + & $1: 20$ & $<500$ & $53.0 \%$ & $9.17 /+$ & alive \\
\hline 27 & mild & + & $1: 80$ & $3.05 \times 10^{3}$ & $67.0 \%$ & $8.79 /+$ & alive \\
\hline 28 & mild & + & - & $3.59 \times 10^{5}$ & $71.0 \%$ & $6.42 /+$ & alive \\
\hline 29 & mild & - & $1: 40$ & $<500$ & $39.0 \%$ & $5.75 /+$ & alive \\
\hline 30 & mild & - & $1: 20$ & $<500$ & $25.0 \%$ & $12.31 /+$ & alive \\
\hline 31 & mild & - & $1: 320$ & $2.63 \times 10^{4}$ & $51.5 \%$ & $14.53 /+$ & alive \\
\hline 32 & severe/EBV-HLH & + & 1:160 & $3.75 \times 10^{3}$ & $97.5 \%$ & $32.82 /+$ & alive \\
\hline 33 & severe/EBV-HLH & - & $1: 320$ & $4.5 \times 10^{7}$ & $100 \%$ & $36.66 /+$ & deceased \\
\hline 34 & severe/EBV-HLH & + & $1: 640$ & $3.05 \times 10^{4}$ & $89.5 \%$ & $39.08 /+$ & deceased \\
\hline 35 & severe/EBV-HLH & + & - & $5.05 \times 10^{4}$ & $91.0 \%$ & $51.03 /+$ & alive \\
\hline 36 & severe/CAEBV & + & $1: 40$ & $8.92 \times 10^{6}$ & $83.5 \%$ & $53.44 /+$ & alive \\
\hline 37 & severe/CAEBV & - & $1: 320$ & $8.26 \times 10^{7}$ & $100 \%$ & $55.34 /+$ & deceased \\
\hline 38 & severe/CAEBV & + & $1: 80$ & $4.75 \times 10^{5}$ & $87.5 \%$ & $48.28 /+$ & alive \\
\hline
\end{tabular}

the EBV DNA genome also provided a quantitative method to identify mild IM or IM-HLH and IM-CAEBV. The FISH assay also allows the in situ localization and visualization of spatial organisation of EBV as they infect cells in their natural habitat. Although the FISH assay detecting the EBV copies is expensive and time consuming, it still appears to be useful for diagnosis of IM and reactivation of EBV. The FISH methodologies can be improved by standardization and commercialization of EBV detection probe and in situ hybridization technique, 


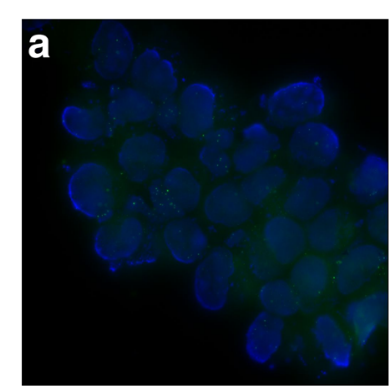

mild IM

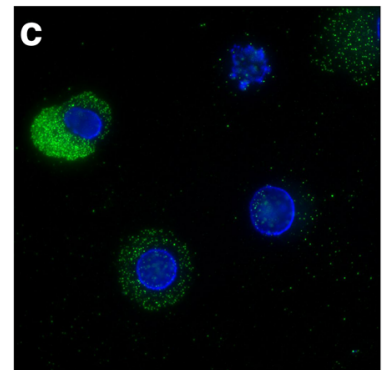

IM-HLH

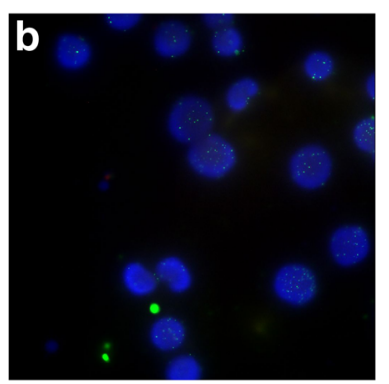

mild IM

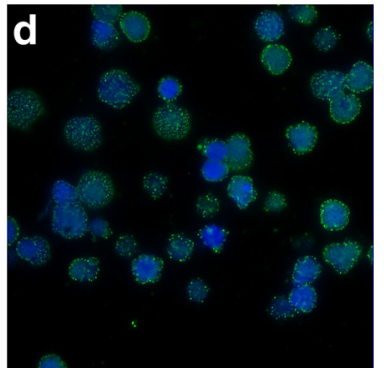

IM-CAEBV
Fig. 3 FISH assay for EBV in IM patients. Fluorescence in situ hybridization for detection of the EBV genome was performed in PBMC of IM patients. $\mathbf{a}$, $\mathbf{b}$ mild IM patients; $\mathbf{c}$, $\mathbf{d}$ IM-HLH or IM-CAEBV

allowing for the adaption to different laboratory's operation. Although the small sample size puts a limitation on the study, there is significant difference in number of fluorescent spot between the mild IM patients and the IM-HLH and IM-CAEBV patients. Future research for gathering more date is needed.

EBV-infected B cells can go on to produce new virions, or the virus can enter a non-productive state known as latency. In the virus productive cycle, the EBV genome is amplified 100- to 1000 -fold by the viral replication machinery. The link between EBV viral load and disease is yet to be determined. Monitoring of the EBV viral load in blood can be an effective method for distinguishing disease-associated EBV reactivation [16, 17]. Purposeful induction of the lytic form of EBV infection is now considered a strategy for the specific destruction of Epstein-Barr virus (EBV)-associated malignancies when the virus is latently infected. However, individuals who experience mononucleosis and high EBV viral load are at an increased risk of developing EBV-positive Hodgkin's lymphoma [18]. The replication of EBV genomic DNA, which exists as a closed circular plasmid, is dependent on chromosomal initiation factors. The latent episome of EBV can also replicate for many generations without significant loss of copy number [19]. This indicates that the elevated viral DNA loads seen in these patients may be associated not only with lytic virus but also with latent virus. Plasma EBV DNA is considered an indicator for the staging and prognosis of nasopharyngeal carcinoma [20]. The EBV DNA load differs in Burkitt's lymphoma patients and IM patients. In Burkitt's lymphoma patients, the EBV DNA load was mainly situated in the cellular compartment, whereas in IM patients, the EBV burden in the circulation was almost exclusively restricted to the cellular blood compartment [21]. A more sensitive FISH than plasma EBV DNA PCR suggested a rapid disappearance of EBV DNA from plasma. The FISH assay detecting the EBV copies in unfractionated whole blood (which includes T cells, B cells and NK cells) is preferred and superior to plasma real-time PCR, as itreflects the absolute viral burden in the patient's circulation. The FISH probe that is more than $3000 \mathrm{bp}$ is preferablefor the detection of the absolute EB viral burden compared to probes that detect EBV-encoded RNAs (EBERs), which are considered a good test for localizing latent EBV in tissue samples.

\section{Conclusions}

Taken together, Molecular tests, including FISH and EBV real-time PCR, are more sensitive than serological assays for the detection of EBV infection. FISH is a sensitive and specific tool for detecting EB viral burden. It can provide useful measurement for the early diagnosis of IM and has comprehensive clinical prospects and value.

\section{Acknowledgements}

This work was supported by National Natural Science Foundation, China (grant number 81272255, 81472695, 81402249); Natural Science Foundation, Hunan (grant number: 2015JJ2181);National Training and Research Base for Talents of principles of carcinogenesis foundation (111 project: 111-2-12).

\section{Availability of data and materials}

All data generated or analysed during this study are included in this published. No any other data available for supplementary materials.

\section{Authors'contributions}

The work presented here was carried out as a collaboration between all authors. PFC, MLZ, WW, BQS and JS carried out most experiments. JJX and GYL made contributions to design, analyze data and interpret data. JJX, BQS and PFC have been involved in drafting the manuscript. JJX and GYL gave most financial support. LJW, YFD and FW collected and assembled the data. All the authors have given final approval to publish the manuscript.

\section{Competing interests}

There authors declare that there are no competing interests.

\section{Consent for publication}

All authors of this article have directly participated in the planning and drafting and all authors listed have read and approved the final version including details and images. The written informed consent for the publication has been obtained from all the authors. The patients, parents, and legal guardians were informed about the publication and had signed informed consent forms.

\section{Ethics approval and consent to participate}

The research presented here has been performed in accordance with the Declaration of Helsinki and has been approved by the ethics committee of Xiangya Hospital, Central South University, China (reference number 201212073). The patients were informed about the sample collection and had signed informed consent forms. 


\section{Publisher's Note}

Springer Nature remains neutral with regard to jurisdictional claims in published maps and institutional affiliations.

\section{Author details}

${ }^{1}$ The Key Laboratory of Carcinogenesis of the Chinese Ministry of Health, Xiangya Hospital, Central South University, Changsha, Hunan, China. ${ }^{2}$ The Key Laboratory of Carcinogenesis and Cancer Invasion of the Chinese Ministry of Education, Cancer Research Institute, Central South University, Changsha, Hunan, China. ${ }^{3}$ Department of hematology, Xiangya hospital, Central South University, Changsha, China. ${ }^{4}$ Hunan Key Laboratory of Nonresolving Inflammation and Cancer, Disease Genome Research Center, The Third Xiangya Hospital, Central South University, Changsha, Hunan, China. ${ }^{5}$ People's Hospital of Dezhou, Dezhou, Shandong 253045, China.

Received: 1 October 2016 Accepted: 20 April 2017

Published online: 03 May 2017

\section{References}

1. Vetsika EK, Callan M. Infectious mononucleosis and Epstein-Barr virus. Expert Rev Mol Med. 2004;6(23):1-16.

2. Magaki S, Ostrzega N, Ho E, Yim C, Wu P, Vinters HV. Hemophagocytic lymphohistiocytosis associated with Epstein-Barr virus in the central nervous system. Hum Pathol. 2017;59:108-12.

3. Cohen Jl, Dropulic L, Hsu AP, Zerbe CS, Krogmann T, Dowdell K, Hornung RL, Lovell J, Hardy N, Hickstein D, et al. Association of GATA2 Deficiency With Severe Primary Epstein-Barr Virus (EBV) Infection and EBV-associated Cancers. Clin Infect Dis. 2016;63(1):41-7.

4. McAulay KA, Higgins CD, Macsween KF, Lake A, Jarrett RF, Robertson FL, Williams $H$, Crawford DH. HLA class I polymorphisms are associated with development of infectious mononucleosis upon primary EBV infection. J Clin Invest. 2007;117(10):3042-8.

5. Lawee D. Mild infectious mononucleosis presenting with transient mixed liver disease: case report with a literature review. Can Fam Physician. 2007; 53(8):1314-6.

6. Hess RD. Routine Epstein-Barr virus diagnostics from the laboratory perspective: still challenging after 35 years. J Clin Microbiol. 2004:42(8):3381-7.

7. Matheson BA, Chisholm SM, Ho-Yen DO. Assessment of rapid ELISA test for detection of Epstein-Barr virus infection. J Clin Pathol. 1990;43(8):691-3.

8. Sonke GS, Ludwig I, van Oosten H, Baars JW, Meijer E, Kater AP, de Jong D. Poor outcomes of chronic active Epstein-Barr virus infection and hemophagocytic lymphohistiocytosis in non-Japanese adult patients. Clin Infect Dis. 2008;47(1):105-8.

9. Bartlett A, Williams R, Hilton M. Splenic rupture in infectious mononucleosis: A systematic review of published case reports. Injury. 2016;47(3):531-8.

10. Silins SL, Sherritt MA, Silleri JM, Cross SM, Elliott SL, Bharadwaj M, Le T, Morrison LE, Khanna R, Moss DJ, et al. Asymptomatic primary Epstein-Barr virus infection occurs in the absence of blood T-cell repertoire perturbations despite high levels of systemic viral load. Blood. 2001;98(13):3739-44.

11. Fafi-Kremer S, Morand P, Brion JP, Pavese P, Baccard M, Germi R, Genoulaz $\mathrm{O}$, Nicod S, Jolivet M, Ruigrok RW, et al. Long-term shedding of infectious epstein-barr virus after infectious mononucleosis. J Infect Dis. 2005;191(6):985-9.

12. Niesters HG, van Esser J, Fries E, Wolthers KC, Cornelissen J, Osterhaus AD. Development of a real-time quantitative assay for detection of Epstein-Barr virus. J Clin Microbiol. 2000;38(2):712-5.

13. Bruu AL, Hjetland R, Holter E, Mortensen L, Natas O, Petterson W, Skar AG, Skarpaas T, Tjade T, Asjo B. Evaluation of 12 commercial tests for detection of Epstein-Barr virus-specific and heterophile antibodies. Clin Diagn Lab Immunol. 2000:7(3):451-6.

14. Vouloumanou EK, Rafailidis PI, Falagas ME. Current diagnosis and management of infectious mononucleosis. Curr Opin Hematol. 2012;19(1):14-20.

15. Holman CJ, Karger AB, Mullan BD, Brundage RC, Balfour HH Jr. Quantitative Epstein-Barr virus shedding and its correlation with the risk of posttransplant lymphoproliferative disorder. Clin Transpl. 2012;26(5):741-7.

16. Loghavi S. Quantitative PCR for Plasma Epstein-Barr Virus Loads in Cancer Diagnostics. Methods Mol Biol. 2016;1392:51-61.

17. Ito Y, Suzuki M, Kawada J, Kimura H. Diagnostic values for the viral load in peripheral blood mononuclear cells of patients with chronic active Epstein-Barr virus disease. J Infect Chemother. 2016;22(4):268-71.

18. Hjalgrim H, Smedby KE, Rostgaard K, Molin D, Hamilton-Dutoit S, Chang ET, Ralfkiaer E, Sundstrom C, Adami HO, Glimelius B, et al. Infectious mononucleosis, childhood social environment, and risk of Hodgkin lymphoma. Cancer Res. 2007;67(5):2382-8.

19. Zhou J, Snyder AR, Lieberman PM. Epstein-Barr virus episome stability is coupled to a delay in replication timing. J Virol. 2009;83(5):2154-62.

20. Shao JY, Zhang Y, Li YH, Gao HY, Feng HX, Wu QL, Cui NJ, Cheng G, Hu B, $\mathrm{Hu}$ LF, et al. Comparison of Epstein-Barr virus DNA level in plasma, peripheral blood cell and tumor tissue in nasopharyngeal carcinoma. Anticancer Res. 2004;24(6):4059-66.

21. Stevens SJ, Pronk I, Middeldorp JM. Toward standardization of Epstein-Barr virus DNA load monitoring: unfractionated whole blood as preferred clinical specimen. J Clin Microbiol. 2001;39(4):1211-6.

\section{Submit your next manuscript to BioMed Central and we will help you at every step:}

- We accept pre-submission inquiries

- Our selector tool helps you to find the most relevant journal

- We provide round the clock customer support

- Convenient online submission

- Thorough peer review

- Inclusion in PubMed and all major indexing services

- Maximum visibility for your research

Submit your manuscript at www.biomedcentral.com/submit
) Biomed Central 